\title{
Estudo sobre o estado de alteração de alguns monumentos portugueses *
}

1. O Laboratório de Mineralogia e Petrologia do Instituto Superior Técnico da Universidade Técnica de Lisboa e o Laboratório do Instituto de José Figueiredo do Ministério da Cultura vêm realizando, em colaboração, estudos sobre a caracterização dos estados de alteração de alguns monumentos portugueses e, em face dos casos analisados, têm proposto os convenientes tratamentos a serem executados pela Direcção-Geral de Edifícios e Monumentos Nacionais do Ministério do Equipamento Social.

A capacidade destes laboratórios vai desde a possibilidade de realizar estudos minerográficos por microscopia com luz transmitida e com luz reflectida, análises químicas de elementos maiores e menores utilizando fluorescência dos raios-X, até determinações por espectrofotometria no domínio do visível, do ultra-violeta e do infravermelho. Há ainda a possibilidade de usar técnicas termo-diferenciais e termo-poderais e radiográficas (difracção e difractomętria dos raios-X). Estão rotinados para a determinação de grandezas físicas caracterizadoras de rochas, como a porosidade, permeabilidade, módulo de elasticidade e tensão de rotura. Podem usar-se, ainda, ensaios de envelhecimento acelerado de rochas o que permite averiguar a alterabilidade de provetes de rochas colhidas em pedreiras para futuros restauros em monumentos. É ainda possivel estudar ao microscópio, segundo cortes convenientes, crostas finas de diversa origem que atapetam certas zonas dos monumentos ou partes relevantes deles como estátuas, retábulos, etc.

2. Podem referir-se alguns estudos que se consideram paradigmáticos da actividade conjunta realizados desde há alguns anos.

Assim referir-se-ão os casos de:

2.1. Palácio do Raio, na cidade de Braga

2.2. Paço de sub-Ripas, na cidade de Coimbra

2.3. Claustro do Silêncio e Capela de S. Teotónio na Igreja de Santa Cruz, na cidade de Coimbra

2.4. Claustro do Convento de Celas, na cidade de Coimbra

2.5. Portais sul e poente no Mosteiro dos Jerónimos, na cidade de Lisboa.

\subsection{O Palácio do Raio, na cidade de Braga}

Trata-se de um palácio construído no século XVIII, na época de D. João V, em típica arquitectura barroca. $\mathrm{Na}$ bela fachada rasga-se um portal recortado sobre o qual se eleva um balcão de balaústres ornado de duas esculturas. O andar nobre é embelezado por janelas com molduras de granito lavrado e por varandas em ferro forjado. O palácio está recoberto por belos azule- jos de fundo azul médio com decoraçōes florais estilizadas e arabescos amarelos, castanhos, brancos e roxos (Fig. 1).

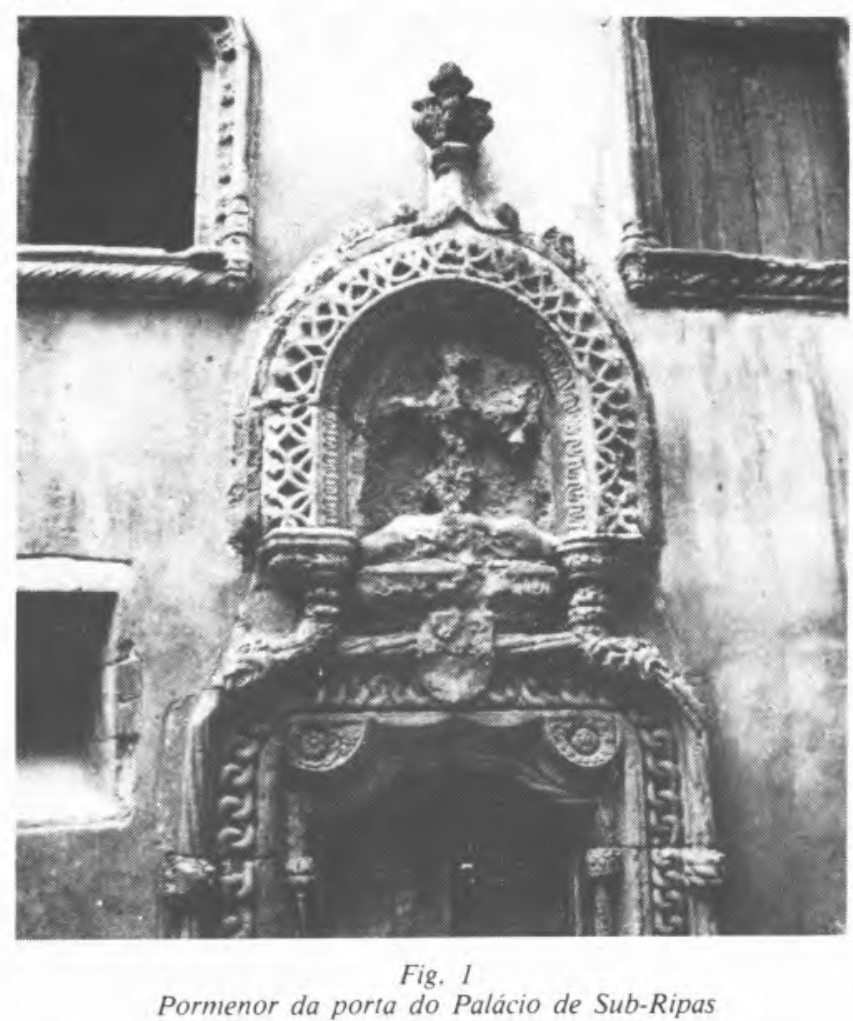

Além da «Fachada principal», virada a nascente, foram ainda examinadas as "Fachada poente» e a «Fachada sul».

Verifica-se, na generalidade, que os azulejos estão em bom estado de conservação mas assentam em parede em mau estado de conservação a avaliar pelo facto de soarem a oco e apresentarem «barrigas». Há casos em que os azulejos estão quase a cair da parede. Mas raramente se verifica que alguns têm o vidrado a destacar-se.

Foi ainda estudada a escadaria principal do palácio onde se observaram eflorescências nas argamassas que deixaram cair alguns azulejos.

Para além dos fenómenos observados nos azulejos (escamação) e da degradação das argamassas, por vezes pejadas de eflorescências, há a referir a alteração das ombreiras graniticas das portas e janelas da «Fachada Principal».

* Comunicação apresentada ao $1 .^{\circ}$ Congresso do Património Construido Luso no Mundo, Lisboa 1987.

a Laboratório de Mineralogia e Petrologia do IST.

b Laboratório Central do Instituto José Figueiredo do IPPC. 
São notáveis os fenómenos de escamação dos granitos que está arenizado, desagregando-se quando raspado com uma espátula. São vulgares as escamas, largas e espessas que se podem obter fazendo «lascar» o granito das ombreiras (Fig. 2).

$\mathrm{O}$ estudo microscópico deste granito mostrou uma rocha granular grosseira a porfiróide, rica de quartzo xenomórfico, de feldspatos alcalinos e de moscovite e biotite. A rocha está muito fina e densamente fissurada (Fig. 3) verificando-se que as microfissuras dos feldspatos estão preenchidas por montmorilonite, embora as plagas dos feldspatos estejam razoavelmente «frescas").

Sendo a montmorilonite um mineral argiloso expansivel os fenómenos sazonais de sacagem-molhagem explicam a escamação ampla e importante verificada.

As eflorescências e a fracção argilosa de granito das ombreiras foram estudadas por várias técnicas mineralógicas e químicas. Os principais factos a referir são, para além da presença da montmorilonite no granito das ombreiras com as consequências mencionadas:

- a presença de montmorilonite na argamassa mais degradada, facilitando a queda dos azulejos;

- a sulfatação quer dos granitos, quer da porta dos azulejos da «Fachada sul» do Palácio;

- a fraca sulfatação da argamassa dos azulejos da «Fachada sul» em contraste com o valor dez vezes maior na parte dos mesmos azulejos;

- a sulfatação das argamassas;

- a presença de cloretos e nitratos nas argamassas de ligação dos azulejos das «Fachada principal» e "Facha-

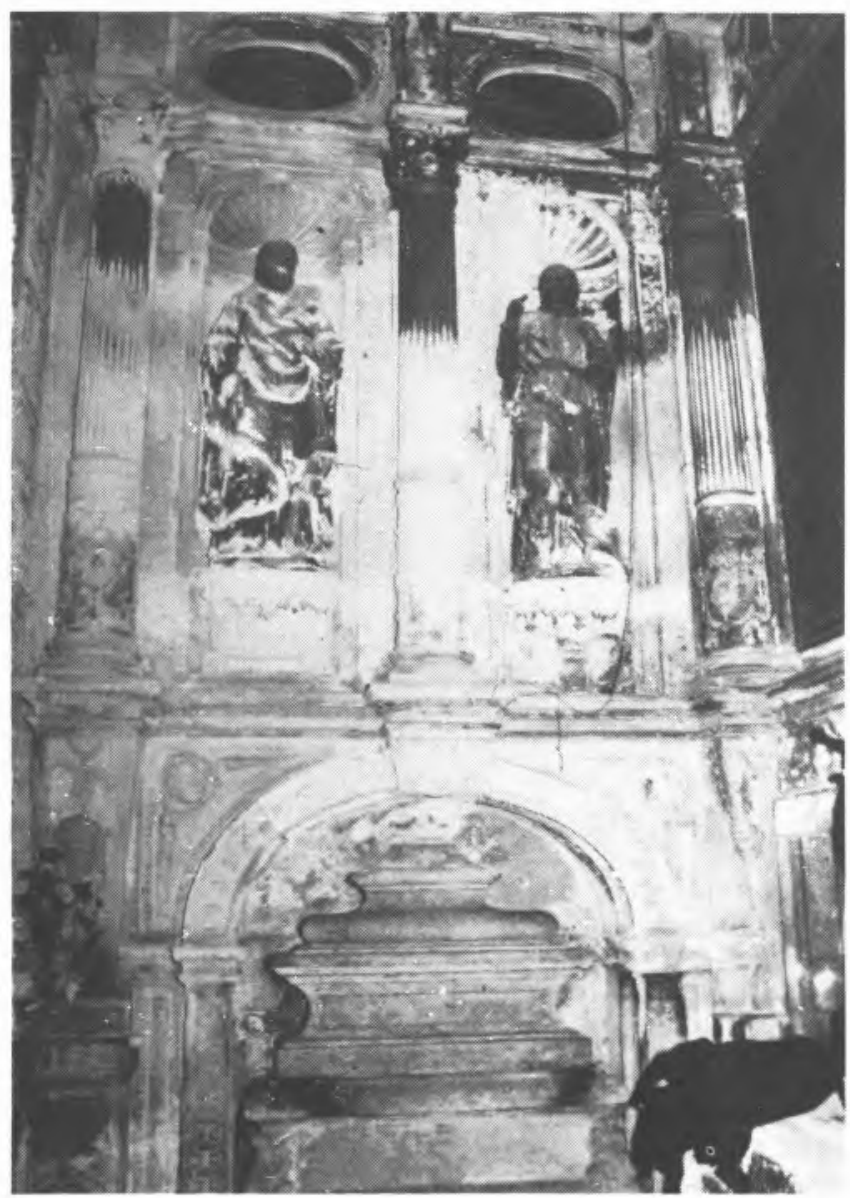

Fig. 2

Capela de S. Teotónio, Igreja de Santa Cruz. Representação do painel esquerdo

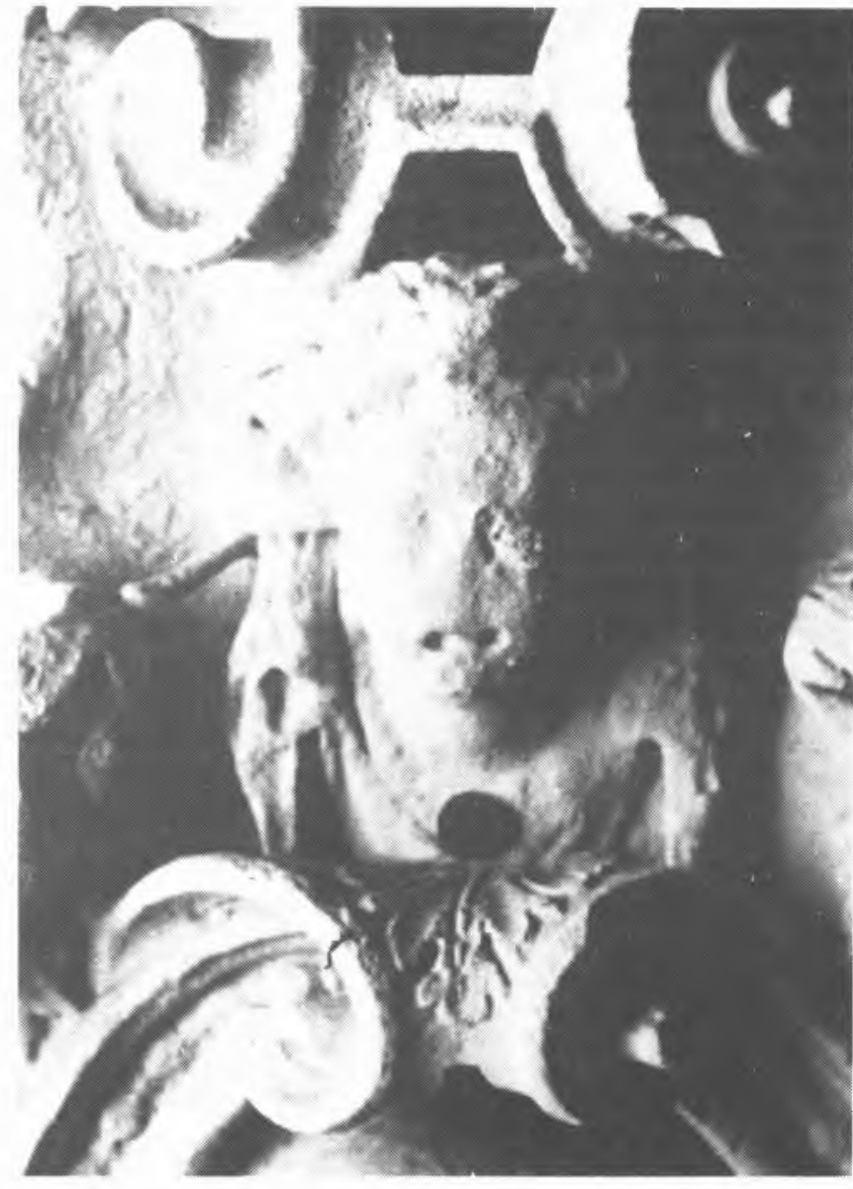

Fig. 3

Pormenor do pelinto esquerdo do Arco Triunfal de acesso à capela de S. Teotónio

da sul», explicando as eflorescências mencionadas; - a relevante quantidade de sulfatos, cloretos, nitratos e nitritos nas argamassas da escadaria principal.

Da conjugação das observaçðes feitas há algumas conclusð̄es e recomendaçð̄es que se apresentam.

Quanto às conclusð̋es, verifica-se que há migração acentuada de sulfatos da argamassa dos azulejos da "Fachada sul» para a pasta dos azulejos provocando a sua deterioração (escamação do vidrado). Nos panos de azulejos da escadaria principal verifica-se que há também migração de sais importantes (sulfatos, cloretos e nitratos) da argamassa para a pasta dos azulejos com as consequências nefastas já referidas.

No que concerne a recomendaçðes:

1) Quanto à substituição da rocha granítica das ombreiras há que a escolher evitando usar rocha aparentemente "sã», mas com minerais argilosos expansivos nas microfissuras.

2) Quanto às paredes revestidas a azulejo, há que evitar a ascensão capilar das águas existentes no sub-solo, em caves do palácio e valas existentes nas imediaçðes (lado sul) procurando drenar tais águas e realizando a revisão das paredes onde estão assentes os painéis de azulejos. Todo o cuidado deve ser posto nas novas argamassas a usar evitando material rochoso com montmorilonite.

\subsection{O Paço de Sub-Ripas na cidade de Coimbra}

Na região de Coimbra abunda um tipo de calcário dolomítico do Jurássico, de tom amarelado e de textura 
oolítica. Este tipo de rocha tem sido usado, ao longo da História, em inúmeros monumentos da cidade de Coimbra. Assim são de citar a Sé-Velha, monumento romântico e ex-libris da cidade, do mesmo modo boa parte da Igreja de Santa Cruz e inúmeros outros monumentos usam este tipo de rocha.

A Casa ou Paço de Sub-Ripas (construída no século XVI) foi sujeita em 1983/84 a profundas obras de beneficiação dado o seu estado de degradação.

Os trabalhos que realizámos dizem respeito ao portal do paço que mostra um belo traçado no estilo manuelino (foto 1).

Verifica-se que este portal e em especial as armas e demais motivos que o ornavam estão forte e generalizadamente degradados, esboroando-se, perdendo os efeitos escultórios as suas formas.

O calcário dolomítico oolítico amarelo mostrou-se fina e generalizada ferruginização. Os oolitos estão soldados entre si por calcite criptocristalina. Todavia a rocha é finamente vacuolar. Sucede que os oolitos estão orlados por fina película argilo-ferro-nitratada. $\mathrm{O}$ efeito de secagem-molhagem leva a que, por fadiga térmica e hidratação-desidratação, a rocha se desagregue. Gera-se assim uma poeira de oolitos resultantes da desagregação da rocha. A origem para os nitratos tem de se procurar, quer na presença de pombos, quer no facto de a cidade ser acidentada e haver hortas e quintais sobranceiros a alguns monumentos e ainda na poluição atmosférica. Assim se pode gerar nitro-amónia e ácido nítrico que actuando sobre a dolomite a transformará em nitrodolomite, sal nitratado do tipo do detectado nas películas debilitadas que orlam os oolitos em vias de desagregação.

O mecanismo geoquímico para a desagregação-decomposição do calcário oolítico amarelo pode ser:

$2 \mathrm{HNO}_{3}+4 \mathrm{H}_{2} \mathrm{O}+(\mathrm{Mg}, \mathrm{Ca}) \mathrm{CO}_{3} \rightarrow(\mathrm{Mg}, \mathrm{Ca})\left(\mathrm{NO}_{3}\right)_{2} \cdot 4 \mathrm{H}_{2} \mathrm{O}+\mathrm{CO}_{2}$

$$
\text { dolomite nitrodolomite }
$$

2.3. Claustros do Silêncio e Capela de S. Teotónio na Igreja de Santa Cruz, na cidade de Coimbra

A igreja de Santa Cruz é um dos mais antigos monumentos do país. Com efeito o mosteiro inicial foi fundado no século XII. Todavia a igreja, tal como hoje a temos, foi reconstituída e profundamente modificada no século XVI, em pleno renascimento português, estando largamente marcada pelo manuelino.

O Claustro do Silêncio é construído com o calcário dolomítico oolítico do Sinemuriano da região. Os casos de desagregação são patentes quer nos umbrais de portais, quer nas rosáceas do fecho de abóbadas e em nervuras destas mesmas abódadas e dos pilares. O tipo de desagregação e os resultados deste fenómeno são idênticos aos descritos para o paço de Sub-Ripas.

No entanto na igreja de Santa Cruz é usada, ainda, outro tipo de rocha: trata-se da «pedra de Ançã». É um calcário branco, fino, oolítico, poroso que permite um lavrado fácil. Este tipo de rocha é usado desde longa data no país como pedra muito pretendida pelos escultores e arquitectos. É usado largamente nas esculturas, púlpitos, túmulos e fachadas de monumentos. É o que sucede na Igreja de Santa Cruz. No próprio Claustro do Silêncio há 3 belos retábulos encastoados nas suas paredes e ilustrando passos da vida de Cristo.

Nestas rochas, os estudos realizados sobre produtos pulveriformes, revelou a presença de sulfatos e mesmo de nitratos. Deve ainda referir-se a presença de cloretos.

Facto notável e que tem de estar sempre presente no estudo deste monumento, diz respeito à cota elevada a que se encontra o nível hidrostático no sub-solo do monumento. No verão ele está a $2 \mathrm{~m}$ do chão da igreja, nos invernos muito pluviosos ele roça esse chão. Em anos de cheias anormais o nivel das águas sobe até atingir a base (ou mais) dos túmulos dos dois primeiros reis de Portugal que se encontram no altar-mor. As águas de um poço aberto na igreja mostram-se cloretadas e nitratadas.

Os casos de desagregação da pedra de Ançã estudados (fotos 2,3) são devidos a ascensão capilar, associada a fortes e dirigidas correntes de ar a que há que juntar acçðes de secagem-molhagem. Em Coimbra registam-se invernos rigorosos e verðes muito cálidos.

Urge uma revisão geral da utilização desta igreja de modo a, por um lado fazer uma drenagem geral e conveniente das águas do subsolo, por outro lado providenciar a que haja remoção de eflorescência, substituição de pedras degradadas, acerto do conteúdo de juntas e ainda cuidados nos circuitos de passagem dos milhares de turistas visitantes do monumento.

\subsection{Convento de Celas}

Trata-se de um convento dos principios do século XII, notável pelo seu pequeno mas precioso claustro romano-gótico, de colunas geminadas e capiteis revestidos de belos alto-relevos. Estes capiteis podem reunir-se em grupos. Assim temos os iconográficos com cenas da Vida de Cristo, os com figuras não hagiográficas, os com decoraçōes de quimeras e os de decoração vegetal.

As peças do claustro, colunas e capiteis, estão talhados em um calcário brando, facilmente trabalhado, da região de Coimbra (foto 4 ).

No que diz respeito ao estado de conservação, há a assinalar colunas e respectivas bases em mau estado de conservação, havendo casos de pulverulência geral, por vezes com diminuição irregular de diâmetro das colunas e ainda pulverulência e fractura da pedra e escamação. Quanto aos capiteis observam-se escamaçðes, perfuraçðes, fracturas, eflorescências e perda parcial da forma. As faces dos capiteis virados a sul e poente são em regra as que se encontram em pior estado de conservação.

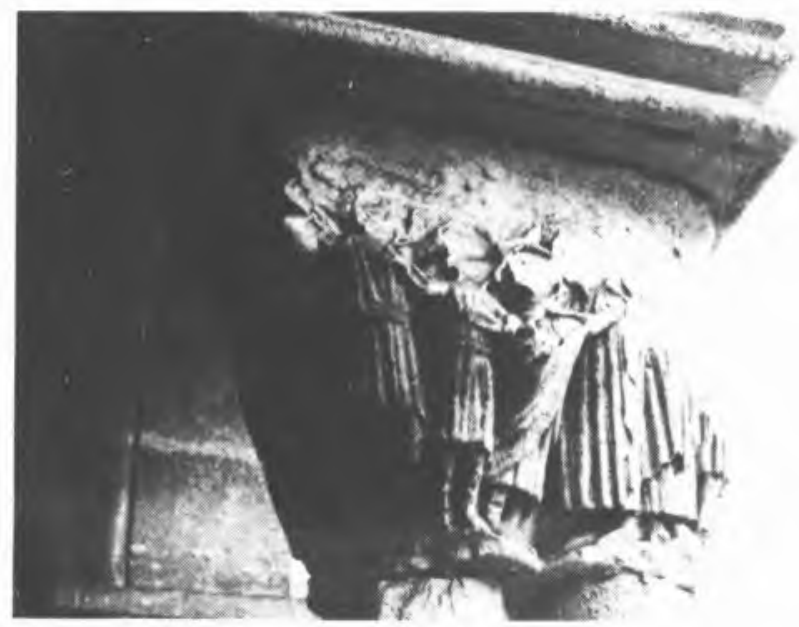

Fig. 4

Capitel em fase inicial de degradação em que são visíveis: pulverulência e perda parcial da forma 
$\mathrm{Na}$ parede sul do claustro, em um nicho rectangular, emoldurado de madeira entalhada, dourada e policromada do século XVII fica um alto relevo com a virgem cercada de anjos. O retábulo em pedra calcária branca de fraca dureza (pedra de Ançã) com $150 \times 80 \mathrm{~m}$ ainda mostra restos de policromia. A policromia foi-se destacando pela pressão dos sais que se formam subjacentemente. O retábulo está coberto por pulverulência geral branca. A moldura de talha está muito desconjuntada e perfurada por insectos.

$\mathrm{O}$ estudo mineralógico e químico dos produtos de alteração das pedras lavradas e das colunas mostra a presença de nitratos, sulfatos e cloretos.

O estudo da estratigrafia da policromia dos capiteis ainda pintados revela, por vezes, sequências de cinco pinturas sucessivas.

Quanto ao tratamento e restauro propostos verifica-se que as colunas deverão ser revistas e substituídas uma vez que se trata de pedra lisa.

Quanto aos capiteis, tratando-se de peças onde há policromia (ou seus vestígios) esta deverá ser consolidada com material filmogénico permeável e dessalinizado localmente por meio de pastas à base de papel e caulino. O retábulo da Coroação da Virgem que se encontra encastoado na ala sul do claustro deve ser desmontado para conveniente tratamento semelhante ao que se referiu para os capiteis. A moldura deverá ser inspeccionada e desinfestada de possiveis insectos.

2.5. Portais sul e poente no Mosteiro dos Jerónimos, na cidade de Lisboa.

Um dos mais belos e mais importantes monumentos portugueses é o Mosteiro dos Jerónimos em Lisboa perto e fronteiro ao Tejo. É um típico exemplar do manuelino (século XVI). A sua construção deve-se a

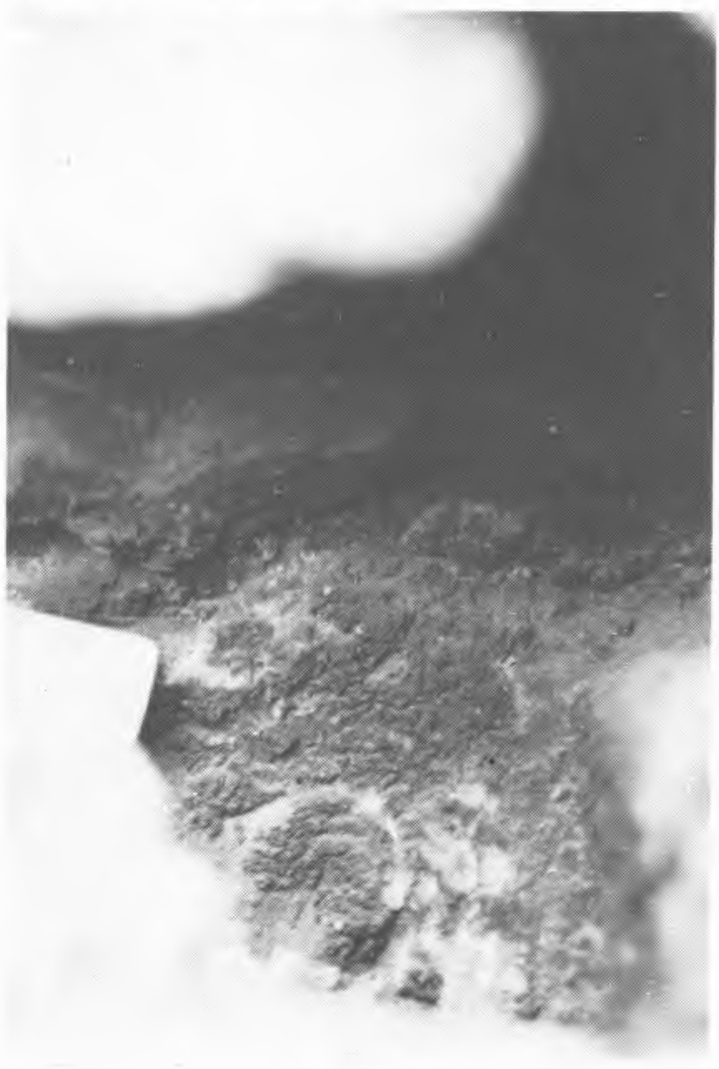

Fig. 5
D. Manuel. Começaremos por nos referir ao Portal de $\mathrm{S}$. Vicente atribuído a Nicolau Chanterène.

Trata-se de um belo portal virado a poente, construído em calcário branco compacto. Sucede que o portal está junto à rua onde o trânsito é intenso e ainda relativamente perto do rio Tejo de onde sopra, diariamente, forte brisa maritima ao fim da tarde.

Verifica-se que as imagens que ornamentam o portal apresentam crostas, umas castanhas, outras negras (fotos 5,6). Muitas vezes estas crostas têm textura frambroidal. Há ainda fracturas e escamação da rocha. $\mathrm{O}$ estudo destas crostas mostra que elas são eflorescências constituídas por gesso e nitratos. O tom castanho deve provir dos hidróxidos de ferro formados por hidratação das argilas ferruginosas existentes no calcário. A dissolução do calcário deixa estes produtos argilo-ferruginosos (terra rossa) que impregnam as crostas gipso-nitrosas e lhes conferem o tom castanho. O estudo microscópico das porçðes negras das crostas mostra que a cor preta é devida à pigmentação carbonosa provocada pela poluição atmosférica.

No portal principal, virado a sul, aparecem zonas ricas de crostas negras (Fig. 7). Examinadas em pormenor estas crostas mostram que, sobre o calcário branco-creme original, se gera crosta acastanhada e sobre esta se despositaram películas anegradas. Verifica-se, ainda, que a formação destas crostas não pára o fenómeno de degradação da rocha subjacente. Com efeito se se estala uma crosta anegrada sob ela aparece uma formação branca incoerente, pulveriforme calcário-gipsífera (Fig. 8).

O estudo microscópico destas crostas negras, evidencia que a película mais exterior está impregnada de pontuaçðes carbonosas e de alcatrão e que, interiormente, aparecem, os hidróxidos de ferro férrico e o gesso.

Estudos já realizados e outros em curso, mostram que há vários tipos de crostas sobre as rochas dos Jerónimos, em especial dos seus dois pórticos principais. Umas são acastanhadas e localizam-se em zonas mais protegidas dos portais. São devidas ao jogo dos fenómenos condensação-evaporação da humidade do ar. As crostas negras ocorrem nas áreas molhadas intermitantemente e são constituídas por gesso, calcite, e partículas carbonosas embebidas naqueles minerais.

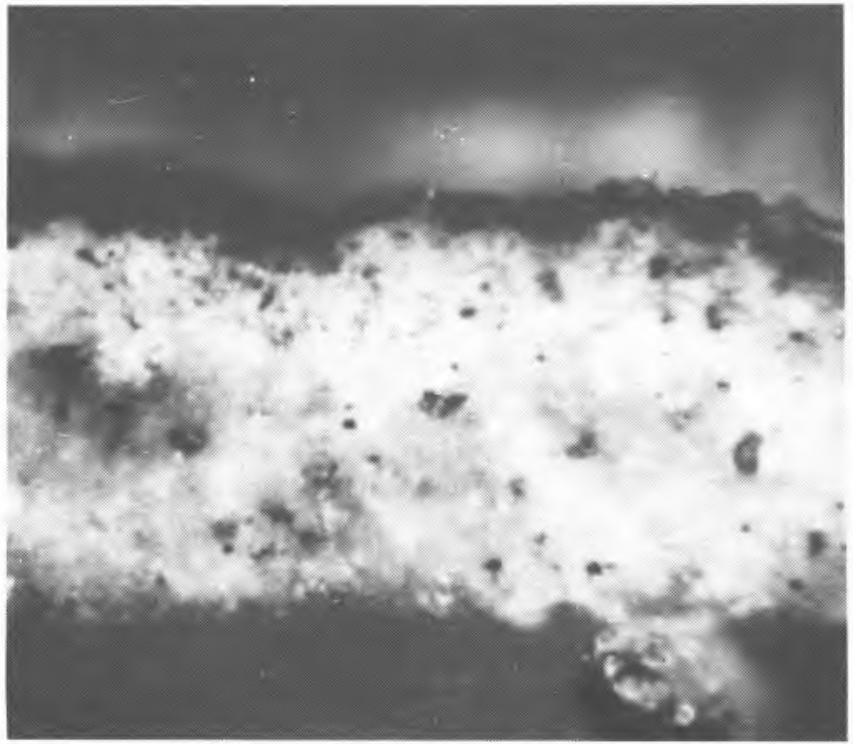

Fig. 6

Aspecto estratigráfico das crostas negras observado em luz reflectida 


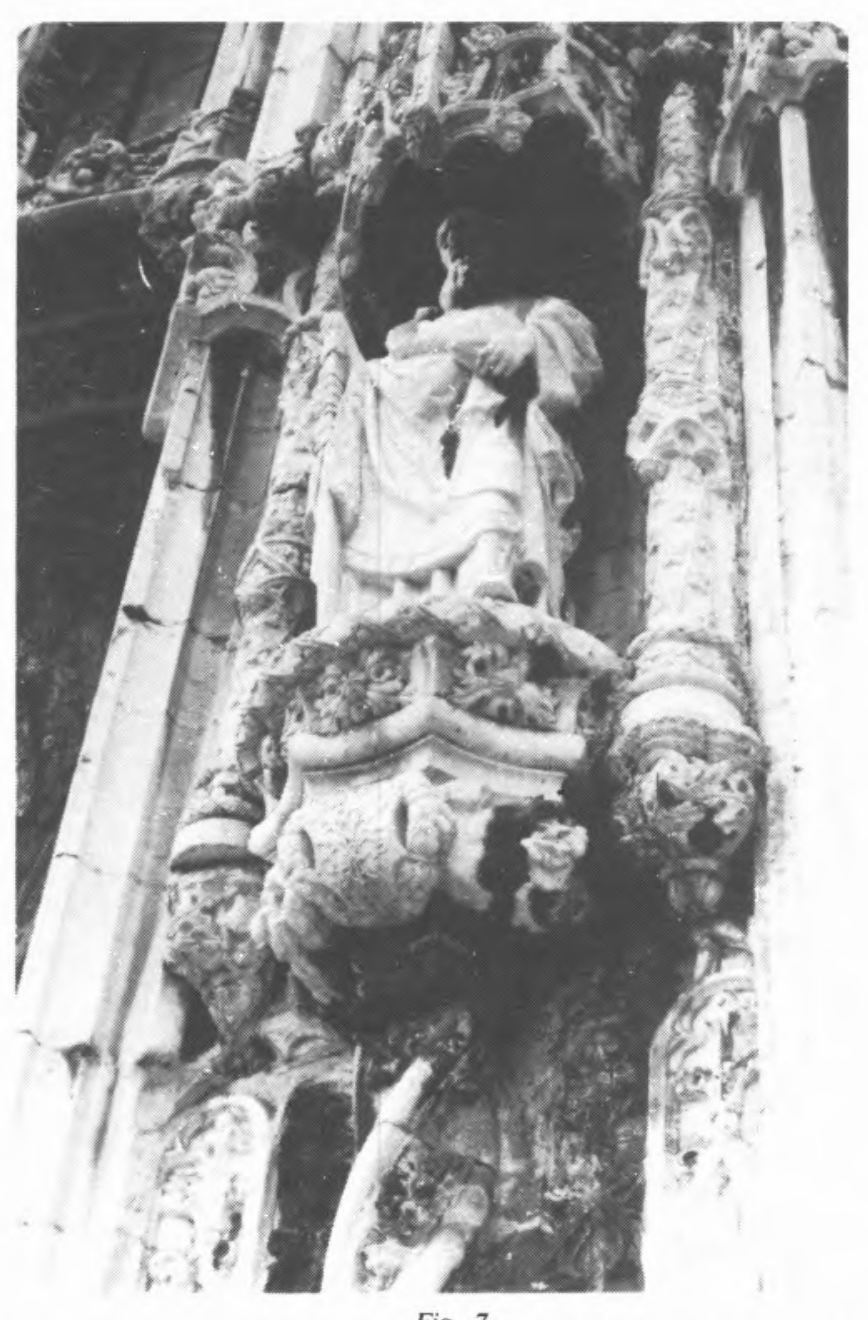

Fig. 7

Pormenor do portal virado a Sul onde são visíveis crostas acastanhadas e negras

Em conclusão diremos que a rocha é vítima de meteorização atmosférica, quer a de origem fluvio-marinha tornando a atmosfera húmida e mesmo ligeiramente hidro-cloretada, quer a terrestre, provocada pelo tráfego que suja e impregna o ar de poeiras carbonosas que são fixadas pelas eflorescências gipso-nitratadas.

Há que limpar o portal e isolá-lo da agressividade da atmosfera reinante no local por meio de anteparo adequado.

\section{Bibliografia}

Aires-Barros, L. (1972) - Análise laboratorial da influência da granularidade na alterabilidade das rochas. "Técnica" Revista de Engenharia, separata do n. ${ }^{\circ} 417$, pp. 65-70, Associação dos Estudantes do I.S.T., Lisboa, 1972.

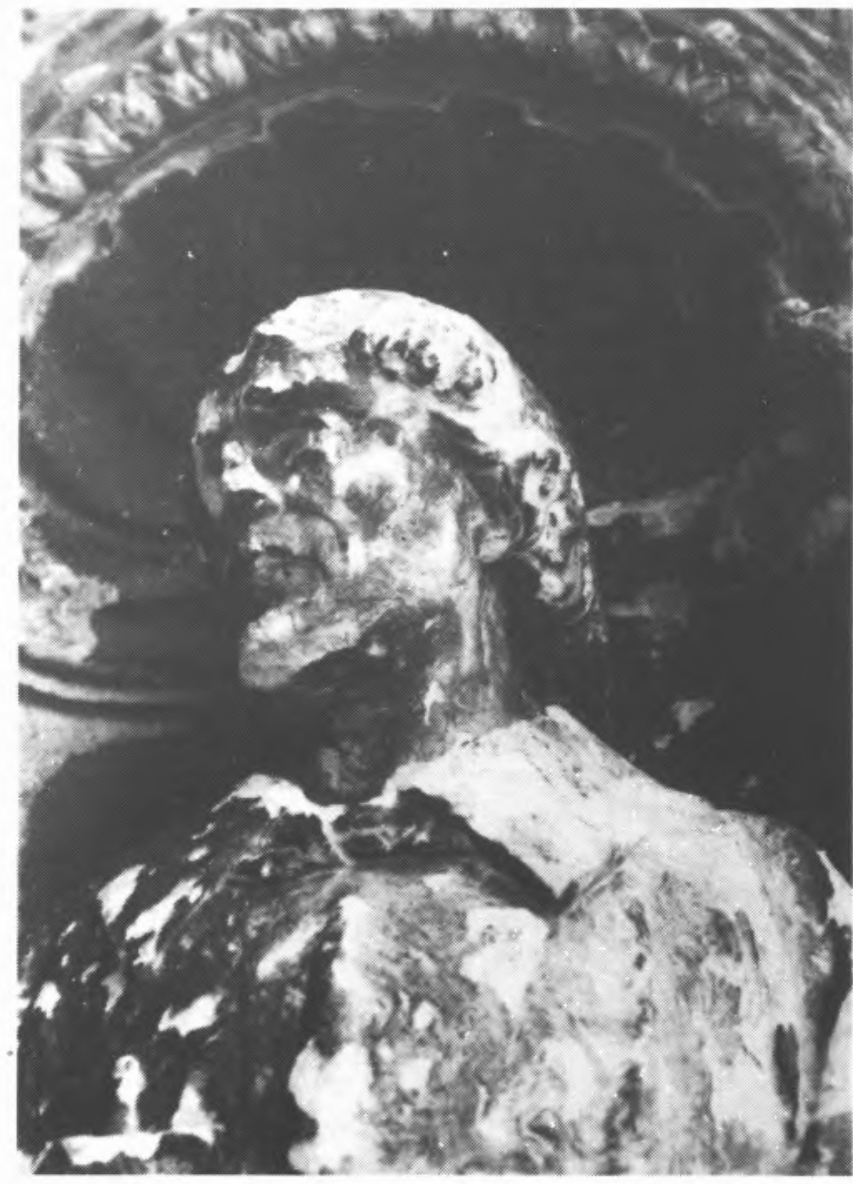

Fig. 8

Visivel a presença de crostas negras. Em alguns locais destacam-se deixando a rocha alterada à vista (pormenor de $S$. Vicente, porta axial)

Aires-Barros, L.; Furtado, S.; Graça, R.C. (1977) - Nota preliminar sobre a geoquímica da alteração do calendário dolomítico empregue na Sé-Velha de Coimbra. Direcção-Geral de Minas e Serviços Geológicos, Serviços Geológicos de Portugal, Lisboa, 1972.

Aires-Barros, L.; Alves, L.M. (1983) - Estudo do tipo de alteração do granito e das argamassas dos azulejos do Palácio do Raio. Relatório interno. Lisboa.

Aires-Barros, L.; Alves, L.M. (1983) - Estudo da alteração de calcários empregues em monumentos de Coimbra. Relatório interno. Lisboa.

Aires-Barros, L.; Alves, L.M. (1984) - Estudo dos fenómenos de alteração ocorrentes no claustro do Silêncio e na capela de S. Teotónio da igreja de Santa Cruz (Coimbra). Relatório interno. Lisboa. Aires-Barros, L.; Alves, L.M. (1984) - Estudo dos fenómenos de alteração ocorrentes no portal axial ou de S. Vicente do Mosteiro dos Jerónimos. Relatório interno. Lisboa.

Aires-Barros, L.; Alves, L.M. (1985) - Estudo dos fenómenos de alteração da pedra usada na Porta Especiosa da Sé-Velha de Coimbra - análise da situação e proposta de tratamento. Relatório interno. Lisboa.

Aires-Barros, L.; Alves, L.M. (1986) - Estudo dos fenómenos de alteração ocorrentes no portal sul (lateral) do Mosteiro dos Jerónimos. Relatório interno. Lisboa. 